American J. of Engineering and Applied Sciences 3 (3): 560-568, 2010

ISSN 1941-7020

(C) 2010 Science Publications

\title{
Spatial-Functional Analysis of Kurdish Courtyard Houses in Erbil City
}

\author{
${ }^{1}$ Faris Ali Mustafa and ${ }^{2}$ Ahmad Sanusi Hassan \\ ${ }^{1}$ Department of Architecture, Salahaddin University-Hawler, Iraq \\ ${ }^{2}$ School of Housing, Building and Planning, University Sains Malaysia, Malaysia
}

\begin{abstract}
Problem statement: This study was to analyze the concept of spatial-function in courtyard house layout and its influence to the cultural and social activities. Themes such as integration, segregation, accessibility and zoning of the building space layout are required to be deliberated, in order to achieve further understanding about the Kurdish social and cultural benchmarks (norms) that might have affected by the spatial configuration of the house layouts. Approach: The study was based on the analysis from selected samples of courtyard house layouts in Erbil city, through adopting the theory of space syntax and its techniques (gamma analysis method). The purpose was to interpret and identify the mutual relationship between space and social life through both scales of spatial-functional analysis. Functionally, illustration and classification of the key zones and sectors of the house; spatially, measuring the main syntactic characteristics of spatial systems (house layouts)and translating it to numerical data in order to identify their effect that forming spatial patterns. Results: The functional approach for the design of residential spaces had a clear impact on the method of formation and organization of residential spaces (functional sectors) through the indicators of physical and intellectual change that affected the nature of spontaneous social interaction in the traditional Kurdish courtyard houses in the city of Erbil. Conclusion: Social variables and factors stemming from the customs and traditions of the community have a direct impact on the residential function through the way of forming and configuration of its interior spaces, which had supported by discovering Genotypic spatial-functional patterns of house layouts (study sample).
\end{abstract}

Key words: Space syntax, courtyard house, gamma analysis, house layout

\section{INTRODUCTION}

Concepts of spatial configuration had been reflected in architectural theory and applications, because it provides a number of evidence about spatial patterns for different societies. In this context, Hillier and Hanson (1989) and Hillier (1999; 2008) has pointed to the emergence of clear evidence emphasizing the weakness of traditional previous interpretations that based on probabilities, considering the architectural forms and spaces as an accidental product of inevitable causes, such as climatic, topographic and ecological factors; without taking into account the social factor. Hillier $(1999 ; 2008)$ in his studies has adopted the theory of space syntax that had been developed by him in Bartlett School of Architecture in University College London (UCL). The methodology of space syntax based on the actuality through the concept of spatial configuration as a relationship between the architectural interior spaces, with an emphasis on the interrelationship between socio-spatial systems; those social relations are not only involved in this interaction, but it may be inherent in the spatial systems itself. The results of this methodology give the function and activity a spatial dimension by numerical values of specific social interpretations (Steadman, 1983; Hanson, 2003). The architectural literatures had adopted the issue of the functional approaches through different views of knowledge about the recruitment of spaces to understand how people use their residential environments through the classification of the daily activities of residents within certain areas and zones (spatial sectors) reflecting the functional approaches for different architectural trends.

The case and the sample: When intending to study the analysis of interior domestic spaces in the traditional houses, the initial question was what sample of houses might be appropriate as data. Kurdish courtyard houses in the old part of Erbil city (Erbil citadel) have been chosen as a case for analysis, in order to achieve research objectives. The principal strategy for the sampling has been to select non-random samples about $10 \%$ of the total traditional courtyard houses, according 
to the purposive sampling method due to considerations regarding the methodology of study (Sekaran, 2002). Thus, it has been selected a sample consist of (36) courtyard house layout during the period 1900-1930. These house layouts had been documented and drawn by the researcher throughout a survey to the old city of Erbil.

\section{MATERIALS AND METHODS}

The methodology of space syntax theory and its techniques through a licensed software programme (syntax exe.) from University College London (UCL) will be applied for measuring the characteristics of different spatial configuration of courtyard houses. The reasons for adopting this methodology in dealing with these characteristics can be identified as follows:

- Analyzing the spatial relations in terms of the basic properties such as (Symmetry-Asymmetry, Distributedness-Nondistributedness) in interpretation the characteristics of different spatial configuration and thus facilitates the process of analyzing and comparison between these various spatial systems

- Combines the physical and social indicators to explain the spatial systems of the buildings (house layouts)

- The ability to evaluate and modeling of different formal and spatial characteristics

Space syntax is an approach developed for analyzing spatial configuration. It aims to describe spatial models and represent these models in a numerical and graphical form; i.e., to interpret them on a scientific basis (Hanson, 2003; Dursun and Saglamer, 2003). The relation between the obtained data (numerical results) in the measuring of syntactic characteristics of spatial configuration of different house layouts will be evaluated in order to identify the effect of these characteristics concerning the spatial configuration of layouts on its genotypic patterns.

Spatial configuration in architecture: Space is a reflection of apparent objective, the elaboration of social and mental processes, whether of individual or society. Societies differ not only in the type of physical forms, but also in the privacy degree of spatial configuration as a prominent cultural dimension (LeviStrauss, 1967; Karlen, 2009). Ordering of space is the purpose of building, not the physical object itself. In this sense, buildings are not just objects, but transformations of space through objects. Therefore, configuration is a fundamental relation of form and space, which is appropriated in the processes, by which buildings are transformed from bodily objects to social and cultural objects (Hillier, 1999). The physical elements in the buildings are clustered to create a particular form; accordingly, the purpose of building is to order the space and the physical component is a means of access to that goal. While the space creates the special relationship between the function and social meaning in the building, so the spatial configuration of building is an organization for the relationships between individuals. Thus, the space can take its distinctive shape by doing two senses:

- Organizing of individuals (people) in the space through the organization of their relations with each other, depending on the degree of separation or aggregation

- Self organization of space through buildings, boundaries, paths, zones and so on; thus, the physical environment of the society takes a particular style. In both senses, society acquires a definite and recognizable spatial order (Hillier and Hanson, 1989) Spatial configuration is a compilation of spaces as tangible and defined construction in a particular form, which leads to generate certain relations between inside and inside and between inside and outside (Nesbitt, 1996). These relations are numerous and varied, either to be a functional relationship (visual-kinetic), which can be achieved through the element of physical contact (doors), or visual relationships, which can be identified through visual linkage (Mustafa, 2010)

Classification of spatial-functional sectors (zones) of the house: For the classification of spatial-functional sectors of the house, it is necessary to refer to previous studies, which conducted on this aspect specifically, such as the study of Gottlieb (1968), which classified the spatial sectors into three functional zones: living, sleeping and service; while, Great Britain Ministry of Housing and Local Government (1969) has divided the spaces into five functional areas such as: Living, dining, sleeping, kitchen and utility; as for Pollowy (1977) has classified the main sectors within three functional areas are: Family, private and service spaces; the study of Spence (1985) classified the spaces and activities into four functional zones are: quiet, noisy, dining and formal spaces for reception and living; as for Talcott et al. (1986) have classified the spatial sectors into three functional areas: Living, sleeping and service spaces. However, most of these studies have directly addressed 
the functional activities in terms of occupancy only, through virtual models of the daily experiences of residents, without any clear standards can be adopted for testing and measuring. Hence, there is a need to adoption empirical studies, which depend in their methodology on applicable and tangible methods such as applications and techniques of space syntax theory; such as the studies of Amorim (1997; 2001) which classified the spatial sectors into four functional sectors: Social, private, service and the mediator (transitional) sectors. Amorim (1997; 2001) has addressed the functional zones and occupancy together, through the actual patterns of the experience of daily living, depending on clear standards gives comprehensive and accurate results can be applied to test our local community. From this standpoint, the objective of this study is to test the Kurdish traditional courtyard house layouts in the old city of Erbil, in order to address the changes which may take place in the layout of modern houses, through the detection of genotypic patterns of their spatial-functional systems to indicate the existence of the influence of socio-cultural changes.

Research analysis: The research uses two scales, which are functional and spatial scale. Both scales can be summarized as follows.

Functional scale: According to this measurement, functional zones (sectors) can be classified into four key types as follows, (Fig. 1):

- $\quad$ Social sector (S): Including spaces of living, dining and reception, this group of spaces allows for continuous interaction among the inhabitants and visitors

- Private sector (P): Including bedrooms and studying spaces, which assure the necessary seclusion of the family and its members

- Service sector (Se): Including the activities related to the reproduction and maintenance of a dwelling's life such as kitchen, storage and servants' accommodation
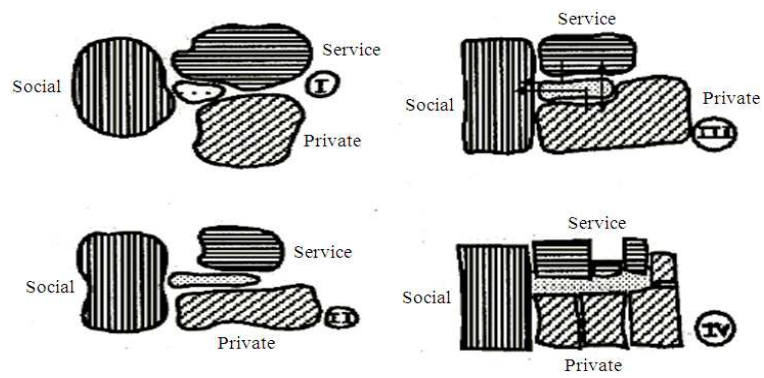

Fig. 1: Classification of the key functional sectors (zones) of the house (Amorim, 1997)
- Mediator or transitional sector (M): Connecting this sector to the functional sectors with each other, such as corridors and stairs

Spatial scale: Based on the methodology of the theory of space syntax, the measuring of the spatial system depends on the following indicators:

- Integration Degree of space Real Relative Asymmetry (RRA): This variant is associated with property of (symmetry-asymmetry), which reflects the (Relative Depth) of space in relation to the rest of spaces in the system; it is a global measurement (Hillier, 1993). An integration degree of space can be calculated in accordance to the following steps.

Firstly: Calculating the Mean Depth of Space (MD) as follows:

- Create a Justified-Graph by putting the intended space to measure its relative depth at the base of the layout as a key space (root space); the other spaces are then aligned above it in levels according to how many spaces one must overtake through in order to arrive at each space from the root space. Each space in the system representing by a small circle, while the permeability between spaces are represented by linked lines, (Fig. 2a-c)

- The depth of each space is calculated in the graph from the root space, where the depth of each space represented by the number of spaces that should pass through to transition from the root space to any space in the system

- The depth (1) means that the space is linked directly to the root space, while the depth (2) means that there is one mediator space between that space and the root space and the depth (3) means the existence of two mediator spaces and so on, according to a formula (1):

$\mathrm{M} . \mathrm{D}=\frac{\sum \mathrm{D}}{\mathrm{K}-1}$

Where:

M.D = Mean Depth of space from the root space

$\sum \mathrm{D}=$ Total magnitudes of the depth for all spaces in the building from the root space

$\mathrm{K}=$ Total number of spaces in the graph

Secondly: Calculating integration value of space Relative Asymmetry (RA): This value expresses the relative depth of that space from all others in the graph through the following formula: 
R.A $=\frac{2(\mathrm{M} . \mathrm{D}-1)}{\mathrm{K}-2}$

Where:

R.A = Relative Asymmetry, integration value of space

M.D $=$ Mean Depth of space

$\mathrm{K}=$ Total number of spaces in the graph

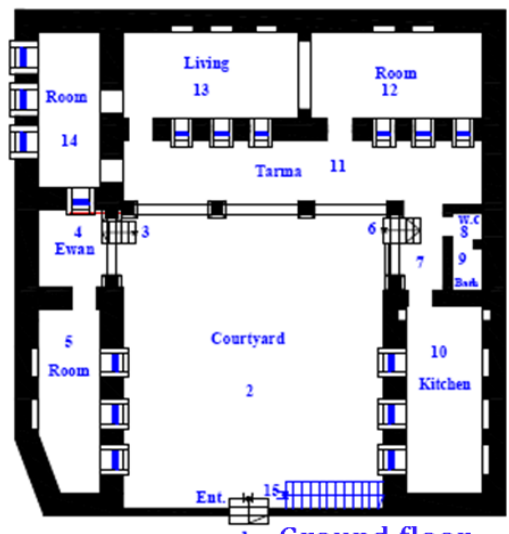

(a)

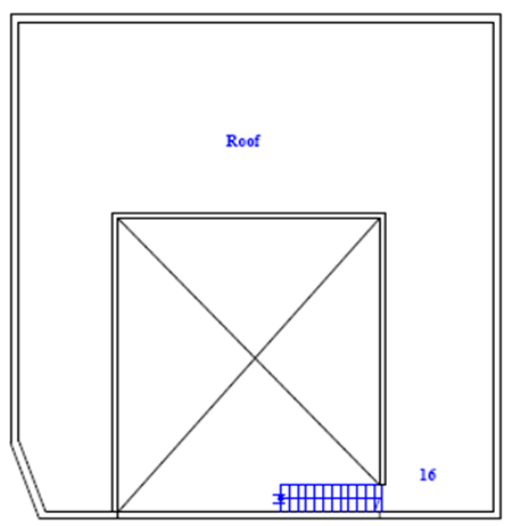

Roof floor

(b)

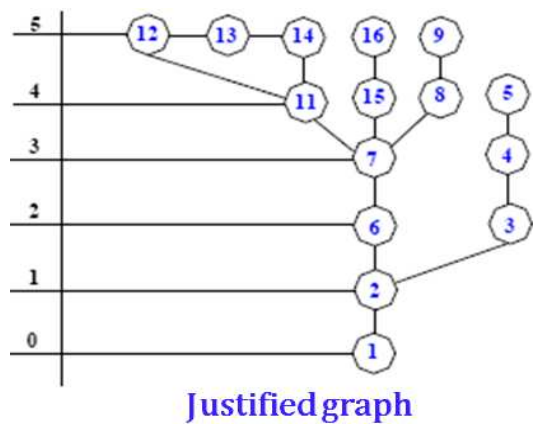

(c)

Fig. 2: A justified graph (c) to represent house layout $(a, b)$
The integration value of space Relative Asymmetry (RA) thus expresses numerically a key aspect of the shape of a justified graph from that space. Integration values (RA) vary between (0) for maximum integration, that is no depth (high-functional efficiency) and (1) for maximum segregation, that is a maximum depth (lowfunctional efficiency) (Hillier et al., 1987a; Onder, 2002; Zako, 2005). The measurements of integration and depth, using the exterior space (of the house) as a root space in relation to the rest spaces in the spatial system. The Depth is a local scale, refers to the number of visualkinetic steps, which separate a determined space from the front door (entrance). This idea refers to the fundamental experience of buildings through the succession (sequence) of the functional sectors (zones) within the house, which could help to understand the impression of people to the concept of front and back. As well as the relationship between open spaces for visitors and those spaces that are specified to the inhabitants (Monteiro, 1997; Toker and Toker, 2003).

Thirdly: Calculating the Real Relative Asymmetry (RRA): The value of RA, resulting from the Eq. 2 must be adjusted for numerical comparison between the spaces of different spatial systems (house layouts); whereas the value of R.A. for each space in the system is adjusted with its value in the depth graph in a Diamond-shaped pattern, or a Pyramid-shaped pattern (Fig. 3).

The depth of diamond shaped representing an intermediate situation between the maximum mean depth of space, when the spaces are organized in the linear sequence in relation to the root space (as mentioned above) and the least mean of the depth when all spaces are linked directly with the root space (Hillier and Hanson, 1989). Thus, the Real Relative Asymmetry (RRA) can be calculated by the following formula:

R.R.A $=\frac{R \cdot A}{D_{K}}$

Where:

R.R.A = Real Relative Asymmetry of space

R.A = Relative Asymmetry of space

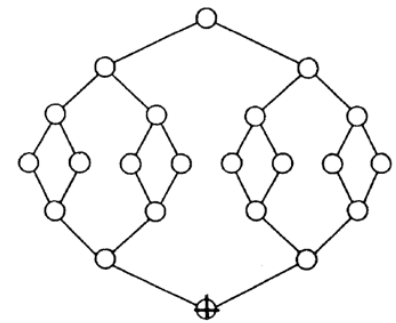

Fig. 3: Diamond-shaped graph used to calculate the integration of spaces (Hillier and Hanson, 1989; Hillier et al., 1987b) 
DK = Relative Asymmetry of space from a Diamondshaped graph

$\mathrm{RRA}=\mathrm{A}$ more sensitive measure of building layouts

R.R.A value varies around the number (1); values of less than (1) refers to the most integrated spaces and less segregation in the system, while the values that more than (1) refers to the most segregated spaces (Hillier and Hanson, 1989; Shoul, 1993; Sungur and Çağdaş, 2003). The relations between functional activities express themselves in space through spatial relationships between spaces of the house, according to an assumption that the properties of integration and segregation are the indicators of the efficiency of space and an indication of the type of functional use the spaces, which occupied by residents. The social interpretation of (RRA) refers to the importance of space with regard to the user (Hillier et al., 1987a; Onder, 2002; Zako, 2005).

Type of space: Measuring the type of space depends on the classification of spaces into four types based on the typological characteristics of these spaces (the way of linking the spaces with each other through openings such as doors and entrances), which meet the functional requirements of occupancy and movement (Hillier, 1999). Accordingly, the classification of spaces, as follows:

- (a-type-space): Single linked space called a deadend cell, like space 7 (Fig. 4a-c). Its relative position does not allow through movement and for that reason privileges as a functional occupation rather than movement, such as bedrooms and study spaces

- (b-type-space): Has two links, intermediates accessibility between two spaces, adding depth to the system, as space 6 (Fig. $4 \mathrm{~b}$ and c)

- (c-type-space): Has more than one link and lie into rings where the number of spaces is the same as the number of connections, they lie into rings, as spaces 2, 3, 4 and 5 (Fig. 4b and c)

- (d-type-space) has more than two links and lies into more than one ring, as space 1. It allows choice for movement and increases accessibility to the graph (Fig. 4b and c) (a)

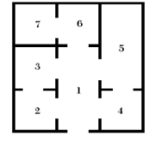

(b)

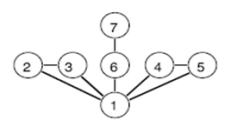

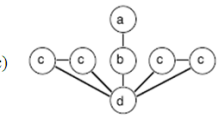

Fig. 4a-c: Classification of spatial patterns (types) for a virtual house layout (Hillier, 1999; Amorim, 1997; 2001)
Accordingly, these spaces form sub-complexes types. A sub-complex is a system formed by a space of a particular type and the adjacent and non-adjacent cells, which qualify the particular space. In Fig. 5, spaces 7 and 6 form a (a-type sub-complex); spaces 6 , 7 and 1, a (b-type sub-complex); spaces 2, 3 and 1 and spaces 4, 5 and 1, a (c-type sub-complexes); finally, spaces 1 to 5, a (d-type sub-complex).

Distribution of sub-complex patterns of spaces that mentioned earlier can be used in the distribution of the various key sectors of the house according to Amorim (1997; 2001) studies as follows:

- Social sector: Including spaces of living, dining and reception

- Service sector: It includes spaces of a kitchen, storage, laundry, sanitary spaces (baths and toilets)

- Both social and service sectors are located within the (c-type sub-complex) and (d-type subcomplex). They have the role of integration the spatial system, which means minimizing the depth of spaces

- Private sector: including bedrooms and studying spaces, located within the (a-type sub-complex). Increasing the depth of spaces (minimizing the integration of the system)

- Mediator or transitional sector: including spaces between various sectors, located within the (c-type sub-complex), connecting sectors with each other

The mediator space is the only element to appear in three different topological situations as follows.

Firstly: As (c-type sub-complex), maximizing the depth of the spatial system of the house.

Secondly: As (b-type sub-complex), it connects the main sectors to the private one.

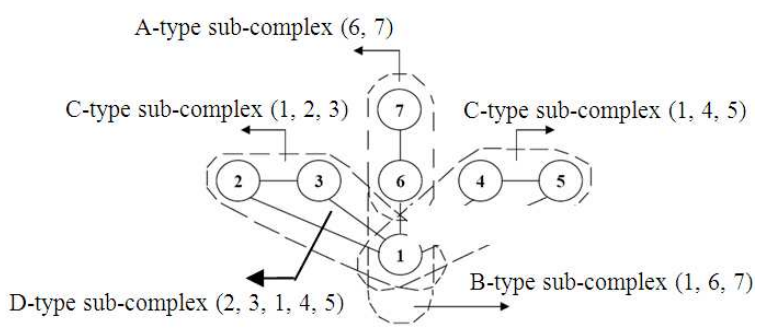

Fig. 5: Sub-complexes classification of spatial patterns of the house (Hillier, 1999; Amorim, 1997; 2001) 
Thirdly: As (d-type sub-complex), when connecting spaces in the same sector such as social and/or service sectors. Furthermore, it becomes as a buffer zone, increasing the depth of the spatial system and isolate the service sector; when located between the main sector (entrance social sector)and service sector, this may transform it from a service sector within a (c-type sub-complex), to a service sector within a (a-type subcomplex) (Amorim, 1997; 2001). Global characteristics of spatial systems depend on the local configuration of cells or types of the existing spaces in the system; in other words, depth minimizing processes will tend locally to (a-type complexes) and globally to (d-type complexes), while depth maximizing processes will tend globally to b-type complexes and locally to small residual (c-type complexes). Essentially, a-and d-type spaces create integration, while (b-and c-type) spaces create segregation. In more general terms, segregation in the building can be achieved by the sequencing of spaces in any spatial system (Hillier, 1999). Consequently, we can conclude that through the application of the indicator analysis (space type), based on the social interpretation, can obtain a clear picture of how the distribution of functional activities in terms of occupancy and movement in the building, because the movement in the spatial complex will be from all parts of the system to all other parts.

\section{RESULTS}

The indicator of space type: The results reveal the presence of spaces in both of social and service sectors always within one ring or more. The spaces of living and kitchen can be categorized into two types of spaces: C-type and d-type. With regard to the space in type (c) constitutes $13.8 \%$ of the samples, while the space in type (d) constitutes $86.11 \%$ of the samples. As for the bathroom space, it has appeared in all samples of type (a). This can be explained socially, living and kitchen spaces representing surfaces for contact between residents and visitors, allow a penetration movement through it to ensure its functional integration as public activities such as sitting, chatting and watching television. The private sector appears in type (a) forming $100 \%$ of the samples. The private sector represents segregated spaces does not allow penetration movement, to provide more privacy and a high degree of control because of the nature of these spaces which allocated to specific activities such as sleeping and studying (Table 1).

\section{The indicator of depth:}

- The social sector represents one of the most functional shallowness sectors, about (100\%) of the samples
- The service sector can be categorized into two types: A service sector (kitchen), it seems as a shallow sector in $100 \%$ of the samples; the service sector (bathrooms and toilets) seems in semishallow depth about 36.8 and $36.1 \%$ for the deep cases of samples

- The samples show coherent spatial patterns, while the kinetic paths permeate the service sector (kitchen) and the social sector (living). Thus be distributed and controlled by mediator spaces (Table 2)

The indicator of integration: This indicator has shown the following results:

- The functional sector is the most integrated sector in the spatial structure of the house (100\%), according to the integration values which ranging between $(0.25-0.75)$

- The service sector is a segregated and semisegregated functional sector, about $88.8 \%$ of the samples and the integration values ranging between (0.75-1.76); except the samples of the type (II) number (4), where the service sector has emerged as an integrated functional sector according to their integration values, which ranging between $(0.25$ 0.47 )

- The private sector is the most segregated functional sectors in the spatial structure, about $88.8 \%$ with integration values ranging between (1.127-1.76); except the samples of the type (5) number (4), where the private sector has emerged as semi integrated about $11.11 \%$, with integration values ranging between $(0.36-0.47)$ (Table 3$)$

Table 1: The indicator of space-type for the functional sectors of house layout

\begin{tabular}{|c|c|c|c|c|c|c|c|c|c|}
\hline \multirow[b]{3}{*}{ Patterns } & \multicolumn{9}{|c|}{ Functional sectors } \\
\hline & \multicolumn{2}{|l|}{3 Private } & \multicolumn{2}{|c|}{4 Service } & \multicolumn{3}{|c|}{5 Social } & \multicolumn{2}{|c|}{6 Mediators } \\
\hline & M1 M2 & M3 & $\mathrm{S} 1$ & $\mathrm{~S} 2$ & $\mathrm{Se} 1$ & $\mathrm{Se} 2$ & $\mathrm{Se} 3$ & P1 & $\mathrm{P} 2$ \\
\hline 1 & d d & & $\mathrm{d}$ & & $\mathrm{c}$ & a & & $\mathrm{a}$ & \\
\hline 2 & $\mathrm{~d}$ & & $\mathrm{~d}$ & & $\mathrm{c}$ & $\mathrm{a}$ & $\mathrm{a}$ & $\mathrm{a}$ & \\
\hline 3 & $\mathrm{~d}$ & & $\mathrm{~d}$ & & $\mathrm{c}$ & $\mathrm{a}$ & a & $\mathrm{a}$ & $\mathrm{a}$ \\
\hline 4 & $\mathrm{~d}$ & $\mathrm{~d}$ & $\mathrm{~d}$ & & $\mathrm{c}$ & $\mathrm{a}$ & $\mathrm{a}$ & $\mathrm{a}$ & $\mathrm{a}$ \\
\hline 5 & $\mathrm{~d}$ & d & $\mathrm{c}$ & & $\mathrm{c}$ & $\mathrm{a}$ & a & $\mathrm{a}$ & $\mathrm{a}$ \\
\hline 6 & $\mathrm{~d}$ & $\mathrm{~d}$ & d & & $\mathrm{d}$ & $\mathrm{a}$ & $\mathrm{a}$ & $\mathrm{a}$ & $\mathrm{a}$ \\
\hline 7 & $\mathrm{~d}$ & $\mathrm{~d}$ & $\mathrm{c}$ & & $\mathrm{c}$ & $\mathrm{a}$ & $\mathrm{a}$ & $\mathrm{a}$ & $\mathrm{a}$ \\
\hline
\end{tabular}

Table 2: The spatial depth of the functional sectors for study samples
\begin{tabular}{lllllllllll} 
Type & M1 & M2 & M3 & S1 & S2 & Se1 & Se2 & Se3 & P1 & P2 \\
\hline 1 & 1 & 3 & & 2 & & 2 & 4 & & 4 & \\
2 & 1 & 3 & & 2 & 2 & 3 & 4 & 4 & \\
3 & 1 & 3 & & 2 & 2 & 3 & 4 & 3 & 4 \\
4 & 1 & 3 & 4 & 2 & 2 & 3 & 5 & 3 & 5 \\
5 & 1 & 3 & 4 & 2 & & 2 & 4 & 5 & 4 & 5 \\
6 & 1 & 3 & 4 & 2 & & 2 & 4 & 5 & 4 & 5 \\
7 & 1 & 3 & 4 & 2 & 4 & 2 & 4 & 5 & 4 & 5 \\
\hline
\end{tabular}


Am. J. Engg. \& Applied Sci., 3 (3): 560-568, 2010

Table 3: Integration (RRA) values of the functional sectors for study samples

\begin{tabular}{|c|c|c|c|c|c|c|c|}
\hline Type & Space & Number & RRA & Type & Space & Number & RRA \\
\hline \multirow[t]{7}{*}{1} & $\mathrm{~s}$ & 4 & 0.588 & 5 & $\mathrm{~m} 2$ & 5 & 0.454 \\
\hline & $\mathrm{m} 2$ & 5 & 0.784 & & $\mathrm{~s}$ & 4 & 0.817 \\
\hline & $\mathrm{m} 1$ & 2 & 0.980 & & se 1 & 3 & 0.817 \\
\hline & se1 & 3 & 1.176 & & $\mathrm{~m} 3$ & 7 & 0.817 \\
\hline & $\mathrm{p}$ & 6 & 1.175 & & p1 & 6 & 1.180 \\
\hline & se2 & 7 & 1.175 & & $\mathrm{~m} 1$ & 2 & 1.180 \\
\hline & c & 1 & 1.961 & & $\mathrm{~m} 1$ & 8 & 1.180 \\
\hline \multirow[t]{8}{*}{2} & $\mathrm{~s}$ & 4 & 0.436 & & p2 & 9 & 1.543 \\
\hline & $\mathrm{m} 2$ & 5 & 0.726 & & se3 & 10 & 1.543 \\
\hline & $\mathrm{m} 1$ & 2 & 0.871 & & c & 1 & 1.906 \\
\hline & se1 & 3 & 1.016 & & & & \\
\hline & se2 & 6 & 1.307 & 6 & $\mathrm{~m} 2$ & 5 & 0.545 \\
\hline & se3 & 7 & 1.597 & & $\mathrm{~s}$ & 4 & 0.726 \\
\hline & $\mathrm{p}$ & 8 & 1.597 & & se1 & 3 & 0.726 \\
\hline & c & 1 & 1.961 & & $\mathrm{~m} 3$ & 7 & 0.817 \\
\hline \multirow[t]{9}{*}{3} & $\mathrm{~s}$ & 4 & 0.338 & & p1 & 6 & 1.180 \\
\hline & $\mathrm{m} 2$ & 6 & 0.676 & & $\mathrm{~m} 1$ & 2 & 1.180 \\
\hline & $\mathrm{m} 1$ & 2 & 0.789 & & se2 & 8 & 1.180 \\
\hline & se1 & 3 & 0.901 & & p2 & 9 & 1.543 \\
\hline & p1 & 5 & 1.127 & & se3 & 10 & 1.543 \\
\hline & se2 & 7 & 1.127 & & $\mathrm{c}$ & 1 & 1.906 \\
\hline & se3 & 8 & 1.465 & & & & \\
\hline & p2 & 9 & 1.465 & 7 & & & \\
\hline & $\mathrm{c}$ & 1 & 1.577 & & $\mathrm{~m} 2$ & 5 & 0.377 \\
\hline \multirow[t]{10}{*}{4} & $\mathrm{~m} 2$ & 6 & 0.545 & & s1 & 4 & 0.753 \\
\hline & $\mathrm{s}$ & 4 & 0.726 & & se1 & 3 & 0.753 \\
\hline & se1 & 3 & 0.908 & & $\mathrm{~m} 3$ & 7 & 0.753 \\
\hline & $\mathrm{m} 3$ & 8 & 0.908 & & p1 & 6 & 1.055 \\
\hline & $\mathrm{m} 1$ & 2 & 1.089 & & s2 & 8 & 1.055 \\
\hline & se2 & 7 & 1.271 & & se2 & 9 & 1.055 \\
\hline & p1 & 5 & 1.452 & & $\mathrm{~m} 1$ & 2 & 1.130 \\
\hline & p2 & 9 & 1.634 & & p2 & 10 & 1.431 \\
\hline & se3 & 10 & 1.634 & & se3 & 11 & 1.431 \\
\hline & $\mathrm{c}$ & 1 & 1.816 & & $\mathrm{c}$ & 1 & 1.808 \\
\hline
\end{tabular}

Table 4: Genotypic spatial-functional patterns of house layouts

\begin{tabular}{llll}
\hline Percentage & $\begin{array}{l}\text { No. of } \\
\text { samples }\end{array}$ & $\begin{array}{l}\text { Inherent genotypic } \\
\text { pattern }\end{array}$ & $\begin{array}{l}\text { Pattern (according } \\
\text { to J. graph) }\end{array}$ \\
\hline 66.66 & 24 & $\mathrm{~s}<\mathrm{se}<\mathrm{p}$ & 2 \\
22.22 & 8 & $\mathrm{~s}=\mathrm{se}<\mathrm{p}$ & $5,6,7$ \\
11.11 & 4 & $\mathrm{~s}<\mathrm{se}=\mathrm{p}$ & $1,3,4$ \\
\hline
\end{tabular}

The Results has revealed three genetic functional patterns of spatial structure for the study sample (Table 4 and 5). Accordingly, these genotypic patterns have been organized in descending order as shown in (Table 4).

\section{DISCUSSION}

Social variables and factors stemming from the customs and traditions of the community have a direct impact on the residential function, as they are capable (as the intellectual side of the building) to influence the formation of residential spaces (as the material side of the building). It is a reciprocal process, not only a tendency of architects themselves (functional approaches), but it has a genotypic information which reflects faithfully the local architectural features within the time period covered by the search.

\section{CONCLUSION}

The most important conclusions reached by this study can be summarized as follows:

- The social sector is the most functional integrated sector, more important and less shallow in relation to residents and visitors; this gives an explanation for the role of this sector in providing surfaces for connection between residents and visitors through public social activities such as watching television, chatting and receiving visitors

- The private sector is the most segregated sector, less important and the most deepness regarding the residents only; it provides connection between them through special activities such as sleeping, relaxation and study

- The service sector is a variable sector in its spatial relations with both of previous sectors (social and private sectors); where varies between a segregated sector provides personal activities such as bathing and washing and semi integrated sector providing the activities of storage, food preparation (cooking) 
and dining. This explains the role of this sector in the creation of spatial relations helped to sustain the life within the housing unit

- Spaces of social and service sectors are generating the movement (circulation) within a spatial structure of the house (c-type) and (d-type)

- The private sector represents occupational spaces; this should be in more deepness, containing particular segregated activities such as sleeping, relaxation and study, which require a closed-ended (a-type) spaces

- The mediator sector appears in varying depths, such as entrance and corridors. This sector plays an important role in providing segregation required and necessary for the private sector

- Traditional spaces of courtyard houses can be organized according to global spatial-functional sectors

- Genotypes of traditional spaces of courtyard houses indicate the richness of these spaces in terms of type and classification

- Traditional Kurdish courtyard houses have a high degree of functional flexibility

Consequently, the functional approach for the design of residential spaces has a clear impact on the method of formation and organization of residential spaces (functional sectors) through the indicators of physical and intellectual change that affected the nature of spontaneous social interaction in the traditional Kurdish courtyard houses in the city of Erbil and this confirms the main goal of the search.

\section{REFERENCES}

Amorim, L., 1997. The SECTOR'S paradigm: Understanding modern functionalism and its effects in configuring domestic space. Proceeding of the 1st International Space Syntax Symposium, Apr. 1997, University College London, London, pp: $1-14$.

Amorim, L., 2001. Houses of Recife: From diachrony to synchrony. Proceeding of the 3rd International Space Syntax Symposium, May 7-1, Atlanta, pp: 1-16.

Dursun, P. and G. Saglamer, 2003. Spatial analysis of different home environments in the city of Trabzon. Proceeding of the 4th International Space Syntax Symposium, June 17-19, University College London, London, pp: 1-18.

Gottlieb, L.D., 1968. Environment and Design in Housing. 1st Edn., Macmillan, London, pp: 258.

Great Britain Ministry of Housing and Local Government, 1969. The Family at Home: A Study of hoUseholds in Sheffield. 1st Edn., HMSO, London, pp: 53.
Hanson, J., 2003. Decoding of Homes and Houses. 1st Edn., Cambridge University Press, Cambridge, ISBN: 10: 0521543517, pp: 328.

Hillier, B. and J. Hanson, 1989. The Social Logic of Space. 1st Edn., Cambridge University Press, Cambridge, ISBN: 10: 0521367840, pp: 296.

Hillier, B., 1993. Architecture as theory: Specifically architectural knowledge. Harv. Archit. Rev., 9: 8-27.

Hillier, B., 1999. Space is the Machine: A Configurational Theory of Architecture. 1st Edn., Cambridge University Press, Cambridge, ISBN: 10: 052164528X, pp: 480.

Hillier, B., 2008. Space and spatiality: What the built environment needs from social theory. Build. Res. Inform., $\quad 36$ : 216-230. $\quad$ DOI: $10.1080 / 09613210801928073$

Hillier, B., J. Hanson and H. Graham, 1987a. Ideas are in things: An application of the space syntax method to discovering houses genotypes. Environ. Plann. B: Plann. Des., 14: 363-385.

Hillier, B., J. Hanson and J. Peponis, 1987b. Syntactic analysis of settlements. Archit. Behav., 3: 217-231.

Karlen, M., 2009, Space Planning Basics. 3rd Edn., John Wiley and Sons, Inc., New Jersey, ISBN: 13: 978-0470231784, pp: 240.

Levi-Strauss, C., 1967. Structural Anthropology. 1st Edn., Anchor Books, New York, pp: 413.

Monteiro, C.G., 1997. Activity analysis in houses of Recife-Brazil. Proceeding of the 1st International Space Syntax Symposium, Apr. 1997, University College London, London, pp: 1-14.

Mustafa, F.A., 2010. Using space syntax analysis in detecting privacy: A comparative study of traditional and modern house layouts in Erbil city, Iraq. Asian Soc. Sci., 6: 157-166.

Nesbitt, K., 1996. Theorizing a New Agenda for Architecture: An Anthropology of Architecture Theory 1965-1995. 1st Edn., Princeton Architectural Press, New York, ISBN: 10: 1568980531, pp: 384.

Onder, D.E., 2002. A new housing group for subresidential area in Samarkand: A morphological comparison. Cities, 19: 327-339.

Pollowy, A.M., 1977. The Urban Nest. 1st Edn., Dowden, Hutchinson and Ross Inc., Stroudsburg, pp: 162.

Sekaran, U., 2002. Research Methods for Business: A Skill Building Approach. 4th Edn., Wiley, India, ISBN: 10: 0471203661, pp: 464.

Shoul, M., 1993. The spatial arrangements of ordinary English houses. Environ. Behav., 25: 22-69. DOI: 10.1177/0013916593251002 
Spence, W.P., 1985. Architecture: Design, Engineering, Drawing-Problems and Quizzes. 4th Edn., Bennett and McKnight Publishing Company, Illinois, ISBN: 9780026720502, pp: 152.

Steadman, P., 1983. Architectural Morphology: An Introduction to the Geometry of Building Planning. 1st Edn., Pion, London, ISBN: 10: 0850860865, pp: 276.

Sungur, C.A. and G. Çağdaş, 2003. Analysis of effect of housing morphology on user satisfaction. Proceeding of the 4th International Space Syntax Symposium, June 17-19, University College London, London, pp: 1-7.

Talcott, C.W., D.E. Hepler, P. Wallach and P.R. Wallach, 1986. Home Planners' Guide to Residential Design. 1st Edn., McGraw-Hill, New York, ISBN: 0070283060, pp: 218.
Toker, U. and Z. Toker, 2003. Family structure and spatial configuration in Turkish house form in Anatolia from early nineteenth century to late twentieth century. Proceeding of the 4th International Space Syntax Symposium, June 1719, University College London, London, pp: 1-16.

Zako, R., 2005. The Power of the Veil: Gender Inequality in the Domestic Setting of Traditional Courtyard Houses. In: Courtyard Housing: Past, Present and Future, Edward, B., M. Sibley, M. Hakmi and P. Land (Eds.) Taylor and Francis Group, London, ISBN: 10: 0415262720, pp: 65-70. 